\title{
Polymorphisms of transforming growth factor- $\beta$ signaling pathway and Kawasaki disease in the Taiwanese population
}

\author{
Ho-Chang Kuo ${ }^{1,2,15}$, Yoshihiro Onouchi ${ }^{3,15}$, Yu-Wen $\mathrm{Hsu}^{4}$, Wei-Chiao Chen ${ }^{4}$, Jin-Ding Huang ${ }^{5}$, Ying-Hsien Huang ${ }^{6}$, \\ Ya-Ling Yang ${ }^{7}$, Mei-Chyn Chao ${ }^{4}$, Hong-Ren Yu ${ }^{1,2}$, Yung-Shun Juan ${ }^{8,9}$, Chiu-Ming Kuo ${ }^{10}$, Kuender D Yang ${ }^{11}$, \\ Jung-San Huang ${ }^{12}$ and Wei-Chiao Chang ${ }^{4,13,14}$
}

\begin{abstract}
Kawasaki disease (KD) is a systemic vasculitis associated with cardiovascular symptom. A previous study in the European descent has indicated that genetic variants of the transforming growth factor- $\beta$ (TGF- $\beta$ ) pathway are involved in the KD susceptibility and clinical status. This study was conducted to investigate if polymorphisms in TGF- $\beta$ signaling pathway are associated with KD susceptibility, and the coronary artery lesion formation. A total of 950 subjects (381 KD patients and 569 controls) were investigated to identify 12 single-nucleotide polymorphisms in the TGF- $\beta$ signaling pathway (rs2796817, rs10482751, rs2027567, rs12029576, rs11466480, rs4776338, rs12901071, rs7162912, rs 1438386, rs6494633, rs12910698 and rs4776339) by using TaqMan Allelic Discrimination assay. Our results indicated that rs 1438386 in the SMAD3 is significantly associated with the susceptibility of KD. Additionally, both haplotypes of TGFB2 and SMAD3 were also associated with the risk of KD. This study showed that genetic polymorphisms in TGF- $\beta$ signaling pathway are associated with KD susceptibility, but not coronary artery lesions formation, or intravenous immunoglobulin treatment response in the Taiwanese population.

Journal of Human Genetics (2011) 56, 840-845; doi:10.1038/jhg.2011.113; published online 20 October 2011
\end{abstract}

Keywords: coronary artery lesions; Kawasaki disease; single-nucleotide polymorphism; TGF- $\beta$

\section{INTRODUCTION}

Kawasaki disease $(\mathrm{KD})$ is an acute systemic vasculitis that was first described by Kawasaki et al. in 1974. ${ }^{1}$ It has been the leading cause of acquired heart diseases in children but its etiology remains unknown. ${ }^{2-4}$ It occurs worldwide and mainly affects children less than 5 year old, especially in Asia. The highest incidence was found in Japan, Korea and then Taiwan. ${ }^{5-7}$ The most common and serious complication of $\mathrm{KD}$ is coronary artery lesions (CAL), including myocardial infarction, ${ }^{8}$ coronary artery dilatation/ectasia and coronary artery aneurysm. ${ }^{9}$

The etiology of KD is still unclear and no consistent etiological agent for KD has been identified yet. Although incidence of KD varies in different ethnic population, several lines of evidence have indicated the significant association between genetic polymorphisms and the susceptibility of KD. For example, polymorphisms in the genes including monocyte chemoattractant protein $1,{ }^{10} \mathrm{IL}-10,{ }^{11} \mathrm{CD} 40 \mathrm{~L},{ }^{12}$ IL- $4,{ }^{13}$ CASP3,${ }^{14,15}$ IL-18, ${ }^{16}$ HLA-E,,${ }^{17} C-C$ chemokine receptor $5^{18}$ and inositol 1,4,5-trisphosphate 3-kinase $\mathrm{C}^{19,20}$ have been reported to be involved in the development of KD. However, only few genes from these studies could be deduced in the second populations that support the hypothesis that multiple polymorphic alleles influence the susceptibility and clinical phenotypes of $\mathrm{KD}^{21}$

Shimizu et al. ${ }^{22}$ firstly reported that genetics polymorphisms of transforming growth factor- $\beta$ (TGF- $\beta$ ) pathway including TGFB2, TGFBR2 and SMAD3 associated with KD susceptibility, the development of CAL and treatment response from the European and US population but without KD patient from the Asian population. TGF- $\beta$

${ }^{1}$ Division of Allergy, Immunology and Rheumatology, Department of Pedatrics, Kaohsiung Chang Gung Memorial Hospital, Kaohsiung, Taiwan; ${ }^{2}$ Graduate Institute of Clinical Medical Science, Chang Gung University College of Medicine, Kaohsiung, Taiwan; ${ }^{3}$ Laboratory for Cardiovascular Diseases Center for Genomic Medicine, RIKEN, Yokohama, Japan; ${ }^{4}$ Department of Medical Genetics, College of Medicine, Kaohsiung Medical University, Kaohsiung, Taiwan; ${ }^{5}$ Department of Pharmacology, Medical College, National Cheng Kung University, Tainan, Taiwan; ${ }^{6}$ Department of Pediatrics, Kaohsiung Chang Gung Memorial Hospital and the Graduate Institute of Clinical Medical Sciences, Chang Gung University College of Medicine, Kaohsiung, Taiwan; ${ }^{7}$ Department of Anesthesiology, Kaohsiung Chang Gung Memorial Hospital and the Graduate Institute of Clinical Medical Sciences, Chang Gung University College of Medicine, Kaohsiung, Taiwan; ${ }^{8}$ Department of Urology, Kaohsiung Medical University Hospital, Kaohsiung, Taiwan; ${ }^{9}$ Department of Urology, College of Medicine, Kaohsiung Medical University, Kaohsiung, Taiwan; ${ }^{10}$ Department of Nursing and Operation Room, Chang Gung Memorial Hospital-Chiayi Branch, Chiayi, Taiwan; ${ }^{11}$ Department of Medical Research, Show Chwan Memorial Hospital in Chang Bing, Changhua, Taiwan; ${ }^{2}$ Department of Biochemistry and Molecular Biology, Saint Louis University School of Medicine, Doisy Research Center, St Louis, MO, USA; ${ }^{13}$ Cancer Center, Kaohsiung Medical University Hospital, Kaohsiung, Taiwan and ${ }^{14}$ Center for Resources, Research and Development, Kaohsiung Medical University, Kaohsiung, Taiwan

Correspondence: Dr W-C Chang, Department of Medical Genetics, Kaohsiung Medical University, 100 TzYou First Road, Kaohsiung City 807, Taiwan.

E-mail: wcc@kmu.edu.tw

15These authors contributed equally to this work.

Received 22 June 2011; revised 25 August 2011; accepted 5 September 2011; published online 20 October 2011 
is a multifunctional molecule, which is important in the regulation of cytokine expression and immune responses. ${ }^{23}$ Animal studies from TGF- $\beta$-deficient mice indicated an essential physiological role in the health and disease. ${ }^{24}$ It has been shown that TGF- $\beta$-mediated signaling pathways are mainly via transcription factors, mothers against decapentaplegic, Drosophila, homolog of (Smads), which includes at least three common proteins: Smad2, Smad3 and Smad4. The binding of TGF- $\beta$ to its receptor resulted in the phosphorylation of Smad 2 or Smad3, which heterodimerizes with Smad4. The formation of the Smad complex further translocates to nucleus to regulate the activation of target genes. ${ }^{25}$ In the cardiovascular system which is an important target of KD, TGF- $\beta$ signaling is involved in the pathogenesis of multiple cardiovascular diseases via an aberrant vascular remodeling. Low expression level of endogenous TGF- $\beta$ activity in blood may contribute to the development of atherosclerotic cardiovascular disease. ${ }^{26}$

In this study, we examined the association between the genetic polymorphisms of TGF- $\beta$ pathway and the risk of KD using a casecontrol study in the Taiwanese populations. The relationship of clinical data (CAL and responses of intravenous immunoglobulin (IVIG) treatment) and genetic polymorphisms of TGFB2, TGFBR2 and SMAD3 were also evaluated. Our studies indicated that a genetic polymorphism in SMAD3 influences KD susceptibility in the Taiwanese population.

\section{MATERIALS AND METHODS}

\section{Patients studied}

All subjects studied were children who fulfilled the diagnostic criteria for KD and were admitted at Chang Gung Memorial Hospital-Kaohsiung Medical Center, between 2000 and 2010. All patients were treated with a single infusion of IVIG $\left(2 \mathrm{~g} \mathrm{~kg}^{-1}\right)$ administered over a 12 -h period. Aspirin $\left(3-5 \mathrm{mg} \mathrm{kg}^{-1}\right.$ per day) was administered until all signs of inflammation were resolved or regression of CAL was detected under two-dimensional echocardiography as our previous studies. ${ }^{4,27-29}$ This study was approved by the Institutional Review Board of Chang Gung Memorial Hospital. All the subjects signed the consent form. We excluded patients who did not meet the diagnostic criteria for $\mathrm{KD}$. CAL was defined by the internal diameter of the coronary artery being at least $3 \mathrm{~mm}$ ( $4 \mathrm{~mm}$, if the subject was over the age of 5 years) or the internal diameter of a segment being at least 1.5 times that of an adjacent segment, as observed in the echocardiogram. ${ }^{15,30,31}$ IVIG responsiveness was defined as defervescence $48 \mathrm{~h}$ after the completion of IVIG treatment and no fever (temperature, $>38^{\circ} \mathrm{C}$ ) recurrence for at least 7 days after IVIG with marked improvement or normalization of inflammatory signs. ${ }^{4,32}$

\section{DNA extraction}

Blood cells were subjected to DNA extraction by treating them first with $0.5 \%$ SDS lysis buffer and then protease $\mathrm{K}\left(1 \mathrm{mg} \mathrm{ml}^{-1}\right)$ for digestion of nuclear protein for $4 \mathrm{~h}$ at $60^{\circ} \mathrm{C}$. Total DNA was harvested by using the Gentra extraction kit (QIAGEN, Germantown, MA, USA) followed by $70 \%$ alcohol precipitation. ${ }^{27}$

\section{Genotyping}

Genotyping was carried out using the TaqMan Allelic Discrimination Assay (Applied Biosystems, Foster city, CA, USA) as our previous report. ${ }^{15}$ The PCR was performed by using a 96-well microplate with the ABI9700 Thermal Cycler (Applied Biosystems, Carlsbad, CA, USA). After PCR, fluorescence was detected and analyzed using the System SDS software version 1.2.3 (Applied Biosystems).

\section{Statistical analysis}

SAS 9.1 (SAS, Cary, NC, USA) for Windows was used for analysis. The statistical differences between case and control in genotype and allele frequency were assessed by the $\chi^{2}$-test. Statistical differences in genotype and allele frequency of the KD patients with/without CAL formation were assessed using the $\chi^{2}$-test. Bonferroni correction was used for correcting multiple tests. Linkage disequilibrium was assessed for any pair of SNPs and haplotype blocks were defined using the default setting of the Haploview software 4.1 (Broad Institute, Cambridge, MA, USA).

\section{RESULTS}

A significant association between the genetic polymorphisms in the TGF- $\beta$ signaling pathway and susceptibility to KD

In this study, we recruited a total of 950 subjects including $381 \mathrm{KD}$ patients and 569 controls. Table 1 shows the characteristics of the subjects. The average age in the cases was 1.7 years and that in the controls was 5.7 years. In all, $9.7 \%$ of $\mathrm{KD}$ patients were observed with CAL formation 8 weeks after the disease onset, and $12.9 \%$ of patients were initial IVIG treatment resistant. Previous studies have identified that genetic polymorphisms (TGFB2: rs2796817, rs10482751, rs2027567 and rs12029576; TGFBR2: rs11466480; SMAD3: rs4776338, rs12901071, rs7162912, rs1438386, rs6494633, rs12910698 and rs4776339) influenced KD susceptibility or the coronary artery outcome. ${ }^{22}$ We analyzed the association between the genetic variants and susceptibility or severity of KD. As shown in the Tables $2 \mathrm{a}$ and b, the genotype frequencies of the controls and patients were in the Hardy-Weinberg equilibrium. None of polymorphisms in the TGFB2 and TGFBR2 were found to be significantly associated with the susceptibility of $\mathrm{KD}$ under three genetic models (dominant, recessive or allelic models) (Table 2a). However, one of the seven polymorphisms in SMAD3 (rs1438386) associated with the susceptibility to KD. $P$-value is 0.001 under the dominant model after Bonferroni correction (Table 2b).

Lack of association between the genetic polymorphisms in the TGF- $\beta$ signaling pathway and CAL formation in the KD patients A total of $381 \mathrm{KD}$ patients were genotyped. No polymorphisms in the TGF 2 2, TGFBR2 or SMAD3 were significantly associated with CAL formation in the KD patients (Tables $3 \mathrm{a}$ and $3 \mathrm{~b}$ ). Additionally, we did not find a statistically significant association between the genetic polymorphisms and IVIG treatment response in the Taiwanese children (data not shown). Haplotype analysis was performed using genotype data in this study. There was no significant association between haplotypes and CAL formation or IVIG treatment in the KD patients (data not shown).

\section{Haplotype analysis of TGF $\beta 2$ and $S M A D 3$ in the susceptibility of} KD patients

We further calculated pairwise linkage disequilibrium (Figures 1 and 2) and analyzed haplotypes of TGF 32 and SMAD3, respectively. The haplotype frequency of TGFB2 gene polymorphisms rs10482751/ rs2027567/rs1209576 among the study subjects was shown in Table 4. rs10482751/rs2027567/rs1209576 pairwise allele analysis indicated that $T / G / G$ haplotype had a significant association with the risk of $\mathrm{KD}$ in comparison with the $\mathrm{C} / \mathrm{A} / \mathrm{T}$ haplotype $(P=0.0420)$. Additionally, SMAD3 haplotypes T/A/A and $\mathrm{C} / \mathrm{C} / \mathrm{G}$ in block 1 were also

Table 1 Basal characteristics of patients with Kawasaki disease (KD) and of normal controls

\begin{tabular}{lcc}
\hline Characteristics & Patients with KD & Normal control \\
\hline Number of subjects & 381 & 569 \\
Gender: male, no (\%) & $247(66.8 \%)$ & $314(56.2 \%)$ \\
Age (years) & $1.7 \pm 1.6$ & $5.7 \pm 4.9$ \\
$\quad$ Range (years) & $0-11$ & $0-51$ \\
Coronary artery lesions (CAL) & $37(9.7 \%)$ & \\
Aneurysm formation & $16(4.2 \%)$ & \\
Intravenous immunoglobulin (IVIG) resistant & $49(12.9 \%)$ & \\
\hline
\end{tabular}

aMean \pm s.d. 
Table 2a Genotype frequencies for TGFB2/TGFBR2 single-nucleotide polymorphisms and Kawasaki disease susceptibility

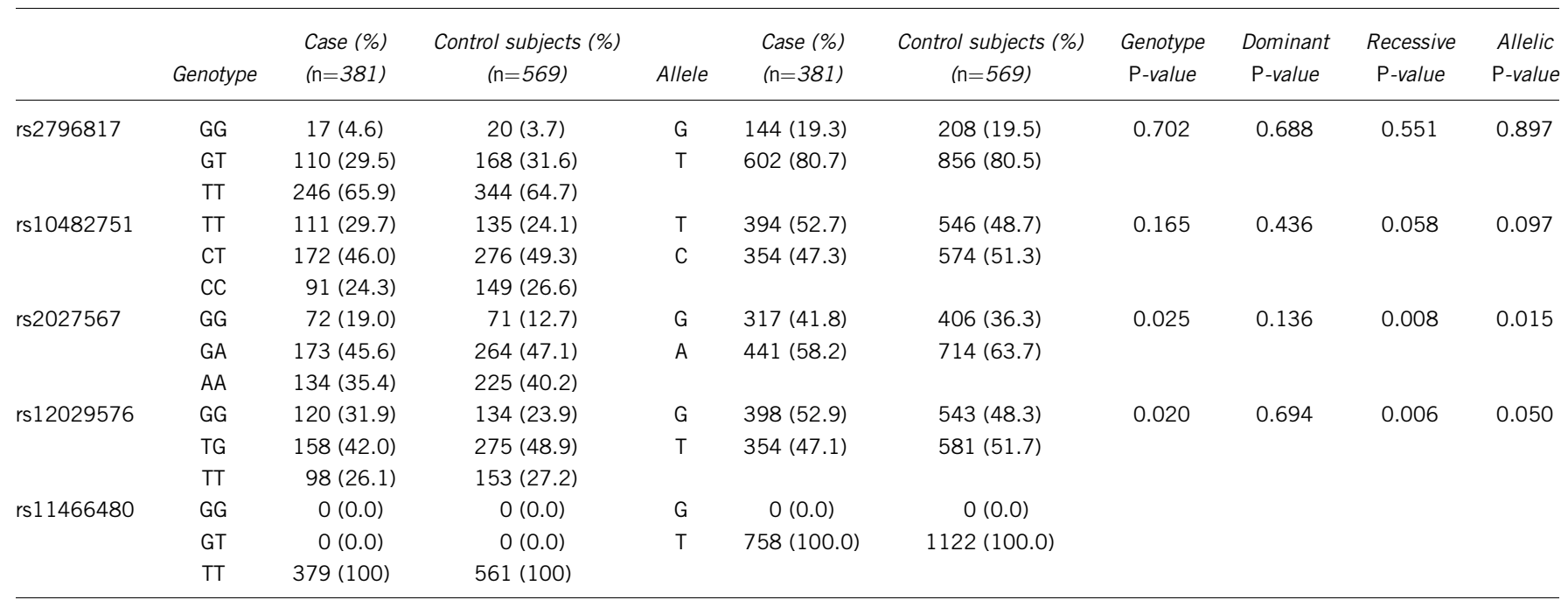

Table 2b Genotype frequencies for SMAD3 single-nucleotide polymorphisms and Kawasaki disease susceptibility

\begin{tabular}{|c|c|c|c|c|c|c|c|c|c|c|}
\hline & Genotype & $\begin{array}{l}\text { Case (\%) } \\
(\mathrm{n}=381)\end{array}$ & $\begin{array}{l}\text { Control subjects (\%) } \\
\qquad(\mathrm{n}=569)\end{array}$ & Allele & $\begin{array}{l}\text { Case (\%) } \\
(\mathrm{n}=381)\end{array}$ & $\begin{array}{l}\text { Control subjects (\%) } \\
\qquad(\mathrm{n}=569)\end{array}$ & $\begin{array}{l}\text { Genotype } \\
\mathrm{P} \text {-value }\end{array}$ & $\begin{array}{l}\text { Dominant } \\
\text { P-value }\end{array}$ & $\begin{array}{c}\text { Recessive } \\
\mathrm{P} \text {-value }\end{array}$ & $\begin{array}{l}\text { Allelic } \\
\mathrm{P} \text {-value }\end{array}$ \\
\hline \multirow[t]{3}{*}{ rs4776338 } & $\mathrm{TT}$ & 72 (19.0) & 110 (19.7) & $\mathrm{T}$ & 348 (45.9) & 507 (45.3) & 0.748 & 0.547 & 0.796 & 0.811 \\
\hline & $\mathrm{TC}$ & $204(53.8)$ & $287(51.3)$ & C & $410(54.1)$ & $611(54.7)$ & & & & \\
\hline & $\mathrm{CC}$ & $103(27.2)$ & 162 (29.0) & & & & & & & \\
\hline \multirow[t]{3}{*}{ rs7162912 } & $A A$ & $56(14.7)$ & $100(18.0)$ & $A$ & 316 (41.6) & $462(41.6)$ & 0.133 & 0.309 & 0.186 & 0.985 \\
\hline & $\mathrm{AC}$ & 204 (53.7) & 262 (47.2) & $\mathrm{C}$ & $444(58.4)$ & $648(58.4)$ & & & & \\
\hline & $\mathrm{CC}$ & 120 (31.6) & 193 (34.8) & & & & & & & \\
\hline \multirow[t]{3}{*}{ rs12901071 } & $\mathrm{GG}$ & $19(5.0)$ & $27(4.8)$ & G & $152(20.1)$ & $229(20.3)$ & 0.949 & 0.827 & 0.872 & 0.902 \\
\hline & $\mathrm{GA}$ & $114(30.0)$ & $175(31.1)$ & $A$ & 604 (79.9) & 897 (79.7) & & & & \\
\hline & $A A$ & $245(65.0)$ & $361(64.1)$ & & & & & & & \\
\hline \multirow[t]{3}{*}{ rs12910698 } & $\mathrm{TT}$ & $50(13.1)$ & $68(12.2)$ & $\mathrm{T}$ & 267 (35.2) & $404(36.1)$ & 0.504 & 0.384 & 0.641 & 0.686 \\
\hline & $\mathrm{TG}$ & $167(44.4)$ & 268 (47.9) & $\mathrm{G}$ & $491(64.8)$ & 714 (63.9) & & & & \\
\hline & $\mathrm{GG}$ & $162(42.5)$ & 223 (39.9) & & & & & & & \\
\hline \multirow[t]{3}{*}{ rs4776339 } & $\mathrm{GG}$ & $51(13.3)$ & 75 (13.4) & $\mathrm{G}$ & 277 (36.4) & 428 (38.2) & 0.481 & 0.250 & 0.998 & 0.413 \\
\hline & $\mathrm{GA}$ & $175(46.2)$ & 278 (49.6) & $A$ & 485 (63.6) & 692 (61.8) & & & & \\
\hline & AA & 155 (40.5) & 207 (37.0) & & & & & & & \\
\hline \multirow[t]{3}{*}{ rs1438386 } & $\mathrm{TT}$ & 109 (29.7) & $113(23.1)$ & $\mathrm{T}$ & 398 (54.2) & $448(45.7)$ & $0.002^{*}$ & $0.001^{*}$ & 0.028 & $0.001^{*}$ \\
\hline & $\mathrm{CT}$ & 180 (49.0) & $222(45.3)$ & $\mathrm{C}$ & 336 (45.8) & $532(54.3)$ & & & & \\
\hline & $\mathrm{CC}$ & 78 (21.3) & 155 (31.6) & & & & & & & \\
\hline \multirow[t]{3}{*}{ rs6494633 } & AA & $0(0.0)$ & $1(0.2)$ & $A$ & $58(7.7)$ & $92(8.2)$ & & 0.697 & & 0.660 \\
\hline & $A G$ & $58(15.2)$ & $90(16.1)$ & $\mathrm{G}$ & 700 (92.3) & $1028(91.8)$ & & & & \\
\hline & GG & $321(84.8)$ & 469 (83.7) & & & & & & & \\
\hline
\end{tabular}

strongly associated with KD susceptibility $(P<0.0001)$ (Table 5). The SMAD3 haplotype rs12910698/rs4776339 (block 2) had no significant association with the risk of $\mathrm{KD}$ (Table 5).

\section{DISCUSSION}

In 2011, a large genetic study has revealed a significant association between the polymorphisms in TGF- $\beta$ pathways and KD susceptibility or coronary artery lesion (CAL) formation in the Europe and US population. ${ }^{22}$ Therefore, a replication study of 12 polymorphisms in 950 subjects was performed in the Taiwanese population. We found a SNP in the SMAD3 (rs1438386) and haplotypes in SMAD3 and
TGFB2 that contribute to the susceptibility of KD. To our knowledge, this is the first analysis to find the association between the genetic variants of TGF- $\beta$ pathways and KD susceptibility in the Asian population. In this study, we recruited only children from the south of Taiwan to avoid heterogeneity. Therefore, the study population was relatively homogenous in terms of age, ethnicity and geographic location.

Several lines of evidence have indicated the role TGF- $\beta$ pathways in the immunity and inflammation. ${ }^{23}$ For example, the activation of $I L-2$ gene could be suppressed by TGF- $\beta$-mediated Smad signaling pathways, and leads to the antiproliferative effects in $\mathrm{T}$ cells. ${ }^{33}$ 
Table 3a Genotype frequencies for TGFB2/TGFBR2 single-nucleotide polymorphisms in patients with coronary artery lesion (CAL) and without CAL

\begin{tabular}{|c|c|c|c|c|c|c|c|c|c|c|}
\hline & Genotype & $\begin{array}{l}C A L(\%) \\
(n=37)\end{array}$ & $\begin{array}{c}\text { Without (\%) } \\
(n=336)\end{array}$ & Allele & $\begin{array}{l}C A L(\%) \\
(n=37)\end{array}$ & $\begin{array}{c}\text { Without (\%) } \\
(n=336)\end{array}$ & $\begin{array}{l}\text { Genotype } \\
\text { P-value }\end{array}$ & $\begin{array}{l}\text { Dominant } \\
\text { P-value }\end{array}$ & $\begin{array}{c}\text { Recessive } \\
\text { P-value }\end{array}$ & $\begin{array}{l}\text { Allelic } \\
\text { P-value }\end{array}$ \\
\hline \multirow[t]{3}{*}{ rs2796817 } & GG & $0(0.0)$ & $17(5.1)$ & $\mathrm{G}$ & $7(10.0)$ & $134(20.3)$ & & 0.066 & & 0.038 \\
\hline & GT & $7(20.0)$ & 100 (30.3) & $\mathrm{T}$ & 63 (90.0) & $526(79.7)$ & & & & \\
\hline & TT & $28(80.0)$ & $213(64.6)$ & & & & & & & \\
\hline \multirow[t]{3}{*}{ rs10482751 } & TT & $10(27.8)$ & $100(30.3)$ & $\mathrm{T}$ & $39(54.2)$ & $351(53.2)$ & 0.707 & 0.546 & 0.754 & 0.874 \\
\hline & $\mathrm{CT}$ & $19(52.8)$ & $151(45.8)$ & $\mathrm{C}$ & $33(45.8)$ & 309 (46.8) & & & & \\
\hline & $\mathrm{CC}$ & $7(19.4)$ & 79 (23.9) & & & & & & & \\
\hline \multirow[t]{3}{*}{ rs2027567 } & GG & $6(16.7)$ & 65 (19.4) & G & $29(40.3)$ & $284(42.4)$ & 0.924 & 0.859 & 0.692 & 0.730 \\
\hline & GA & $17(47.2)$ & $154(46.0)$ & $A$ & $43(59.7)$ & $386(57.6)$ & & & & \\
\hline & $A A$ & $13(36.1)$ & $116(34.6)$ & & & & & & & \\
\hline \multirow[t]{3}{*}{ rs12029576 } & GG & $13(35.2)$ & 106 (32.0) & $\mathrm{G}$ & $42(56.8)$ & 351 (53.0) & 0.835 & 0.701 & 0.564 & 0.541 \\
\hline & $\mathrm{TG}$ & $16(43.2)$ & $139(42.0)$ & $\mathrm{T}$ & $32(43.2)$ & $311(47.0)$ & & & & \\
\hline & TT & $8(21.6)$ & $86(26.0)$ & & & & & & & \\
\hline \multirow[t]{3}{*}{ rs11466480 } & GG & $0(0.0)$ & $0(0.0)$ & G & $0(0.0)$ & $0(0.0)$ & & & & \\
\hline & GT & $0(0.0)$ & $0(0.0)$ & $\mathrm{T}$ & $74(100.0)$ & $668(100.0)$ & & & & \\
\hline & TT & 37 (100.0) & 334 (100.0) & & & & & & & \\
\hline
\end{tabular}

Table 3b Genotype frequencies for SMAD3 single-nucleotide polymorphisms in patients with coronary artery lesion (CAL) and without CAL

\begin{tabular}{|c|c|c|c|c|c|c|c|c|c|c|}
\hline & Genotype & $\begin{array}{c}C A L(\%) \\
(n=37)\end{array}$ & $\begin{array}{l}\text { Without (\%) } \\
\quad(n=336)\end{array}$ & Allele & $\begin{array}{c}C A L(\%) \\
(n=37)\end{array}$ & $\begin{array}{c}\text { Without (\%) } \\
(n=336)\end{array}$ & $\begin{array}{l}\text { Genotype } \\
\text { P-value }\end{array}$ & $\begin{array}{l}\text { Dominant } \\
\text { P-value }\end{array}$ & $\begin{array}{l}\text { Recessive } \\
\mathrm{P} \text {-value }\end{array}$ & $\begin{array}{l}\text { Allelic } \\
\text { P-value }\end{array}$ \\
\hline \multirow[t]{3}{*}{ rs4776338 } & $\mathrm{TT}$ & $9(24.3)$ & 61 (18.3) & $\mathrm{T}$ & $38(51.4)$ & $304(45.5)$ & 0.593 & 0.463 & 0.371 & 0.339 \\
\hline & $\mathrm{TC}$ & $20(54.1)$ & $182(54.5)$ & C & $36(48.6)$ & 364 (54.5) & & & & \\
\hline & $\mathrm{CC}$ & $8(21.6)$ & $91(27.2)$ & & & & & & & \\
\hline \multirow[t]{3}{*}{ rs7162912 } & $A A$ & 7 (18.9) & $47(14.0)$ & $A$ & 31 (41.9) & $278(41.5)$ & 0.543 & 0.611 & 0.423 & 0.947 \\
\hline & $A C$ & $17(46.0)$ & $184(54.9)$ & C & $43(58.1)$ & 392 (58.5) & & & & \\
\hline & $\mathrm{CC}$ & $13(35.1)$ & $104(31.1)$ & & & & & & & \\
\hline \multirow[t]{3}{*}{ rs12901071 } & $\mathrm{GG}$ & $3(8.1)$ & $16(4.8)$ & $\mathrm{G}$ & $13(17.6)$ & $135(20.3)$ & 0.258 & 0.292 & 0.388 & 0.581 \\
\hline & GA & $7(18.9)$ & 103 (30.9) & $A$ & $61(82.4)$ & $531(79.7)$ & & & & \\
\hline & $A A$ & $27(73.0)$ & $214(64.3)$ & & & & & & & \\
\hline \multirow[t]{3}{*}{ rs12910698 } & TT & 5 (13.5) & 43 (12.9) & $\mathrm{T}$ & $24(32.4)$ & 235 (35.2) & 0.723 & 0.475 & 0.913 & 0.638 \\
\hline & $\mathrm{TG}$ & $14(37.8)$ & 149 (44.6) & $\mathrm{G}$ & $50(67.6)$ & $433(64.8)$ & & & & \\
\hline & $\mathrm{GG}$ & $18(48.7)$ & $142(42.5)$ & & & & & & & \\
\hline \multirow[t]{3}{*}{ rs4776339 } & GG & $5(13.5)$ & $44(13.1)$ & $G$ & $25(33.8)$ & 244 (36.3) & 0.779 & 0.521 & 0.943 & 0.668 \\
\hline & GA & $15(40.5)$ & $156(46.4)$ & $A$ & $49(66.2)$ & $428(63.7)$ & & & & \\
\hline & $A A$ & $17(46.0)$ & $136(40.5)$ & & & & & & & \\
\hline \multirow[t]{3}{*}{ rs1438386 } & $\mathrm{TT}$ & $14(38.9)$ & 95 (29.3) & $\mathrm{T}$ & $47(65.3)$ & $347(53.5)$ & 0.129 & 0.052 & 0.236 & 0.058 \\
\hline & $\mathrm{CT}$ & $19(52.8)$ & $157(48.5)$ & C & $25(34.7)$ & 301 (46.5) & & & & \\
\hline & $\mathrm{CC}$ & $3(8.3)$ & $72(22.2)$ & & & & & & & \\
\hline \multirow[t]{3}{*}{ rs6494633 } & $A A$ & $0(0.0)$ & $0(0.0)$ & $A$ & $4(5.4)$ & $53(7.9)$ & & 0.422 & & 0.442 \\
\hline & $A G$ & $4(10.8)$ & $53(15.8)$ & G & $70(94.6)$ & $617(92.1)$ & & & & \\
\hline & GG & $33(89.2)$ & 282 (84.2) & & & & & & & \\
\hline
\end{tabular}

A transcription factor, nuclear factor of activated $\mathrm{T}$ cells, is one of the most important mediated for IL-2 mRNA induction. The activation of nuclear factor of activated $\mathrm{T}$ cells has been shown to be regulated by inositol 1,4,5-trisphosphate 3-kinase C, an important gene in the susceptibility of KD. ${ }^{20}$ Therefore, nuclear factor of activated T cells could be a target of Smad2 and Smad3. In addition, the activation of TGF- $\beta$-mediated signaling pathways is much dependent on the co-mediator Smad4 that forms active complexes to be translocated into the nucleus to regulate the target genes. We did not examine
SMAD4 polymorphisms because it is not as polymorphic as other molecules in the TGF- $\beta$ pathways.

Genome-wide association study for $\mathrm{KD}$ was firstly performed by Burgner et al. ${ }^{21} \mathrm{~A}$ total of 40 SNPs and 6 haplotypes were confirmed in an independent cohort of KD families. They also identified a SNP within $\mathrm{N}$-acetylated alpha-linked acidic dipeptidase-like 2 (NAALADL2; rs17531088) that significantly associated to the susceptibility of KD. In the Asian population, Onouchi et al. ${ }^{20}$ identified the susceptibility loci on chromosome 19q13.2 and further confirmed 


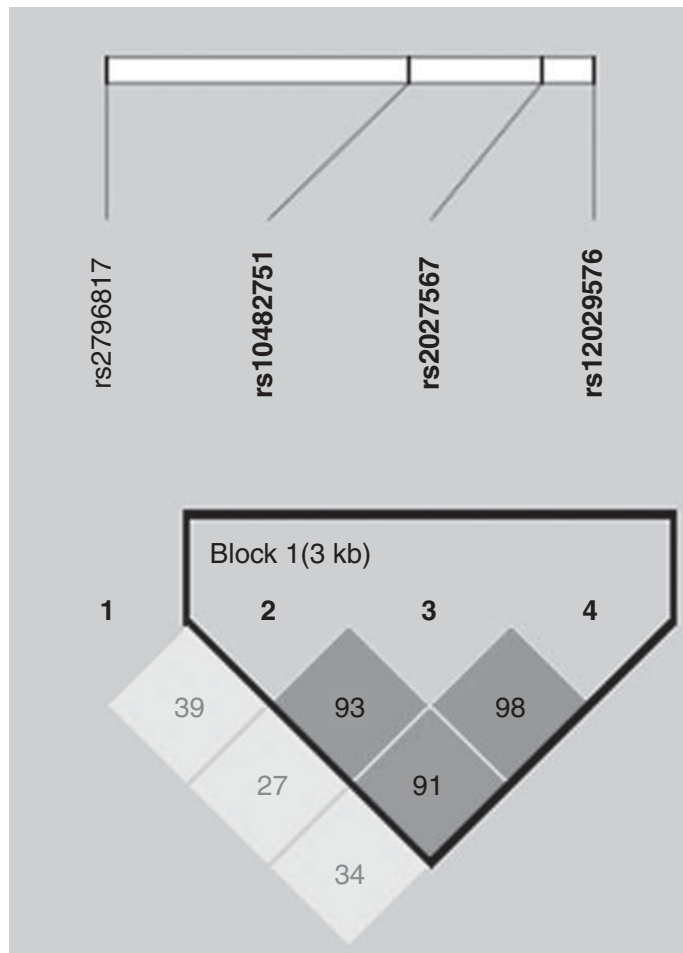

Figure 1 TGFB2 gene linkage disequilibrium and haplotype block structure in KD. The number on the cell is the LOD score of $D^{\prime}$. A full color version of this figure is available at the Journal of Human Genetics journal online.

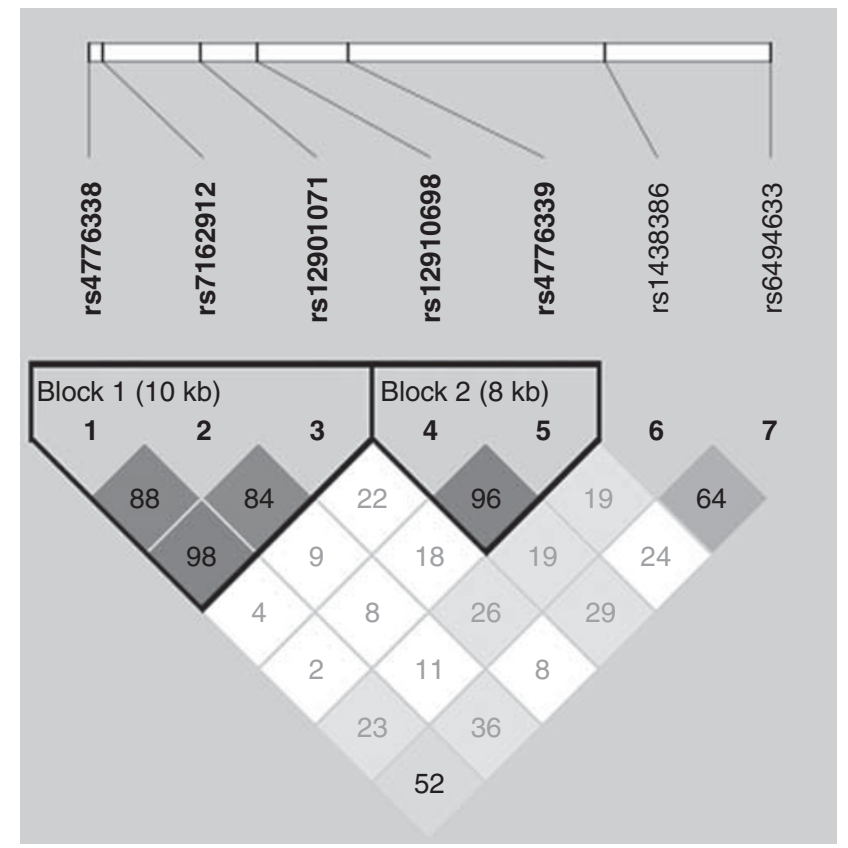

Figure 2 SMAD3 gene linkage disequilibrium and haplotype block structure in KD. The number on the cell is the LOD score of $D^{\prime}$. A full color version of this figure is available at the Journal of Human Genetics journal online.

the functional SNP of inositol 1,4,5-trisphosphate 3-kinase C in the disease activity of KD. Recently, another genome-wide association study was conducted in the Korean population. A total of 786 subjects (186 KD patients and 600 controls) were recruited. A very careful
Table 4 Haplotype frequencies of the TGFB2 gene in controls and patients with Kawasaki disease

\begin{tabular}{lcccc}
$\begin{array}{l}\text { Rs10482751/ } \\
\text { rs2027567/ } \\
\text { rs1209576 }\end{array}$ & $\begin{array}{c}\text { Case (\%) } \\
(\mathrm{n}=381)\end{array}$ & $\begin{array}{c}\text { Control (\%) } \\
(\mathrm{n}=569)\end{array}$ & OR $(95 \% \mathrm{Cl})$ & P-value \\
\hline $\mathrm{T} / \mathrm{G} / \mathrm{G}$ & $294(40.1)$ & $392(35.5)$ & $1.24(1.01-1.52)$ & $0.0420^{\mathrm{a}}$ \\
$\mathrm{C} / \mathrm{G} / \mathrm{G}$ & $9(1.2)$ & $9(0.8)$ & $1.65(0.65-4.19)$ & 0.2902 \\
$\mathrm{C} / \mathrm{A} / \mathrm{G}$ & $9(1.2)$ & $11(1.0)$ & $1.35(0.55-3.29)$ & 0.5102 \\
$\mathrm{~T} / \mathrm{A} / \mathrm{G}$ & $76(10.4)$ & $129(11.7)$ & $0.97(0.71-1.33)$ & 0.8525 \\
$\mathrm{~T} / \mathrm{A} / \mathrm{T}$ & $14(1.9)$ & $21(1.9)$ & $1.10(0.55-2.19)$ & 0.7900 \\
$\mathrm{C} / \mathrm{A} / \mathrm{T}$ & $329(44.8)$ & $542(49.1)$ & Reference & \\
\hline
\end{tabular}

asignificant $(P<0.05)$ values are in bold.

Table 5 Haplotype frequencies of the SMAD3 gene in patients in controls and patients with Kawasaki disease

\begin{tabular}{|c|c|c|c|c|}
\hline & $\begin{array}{l}\text { Case }(\%) \\
(n=381)\end{array}$ & $\begin{array}{c}\text { Control (\%) } \\
(\mathrm{n}=569)\end{array}$ & OR $(95 \% \mathrm{Cl})$ & P-value \\
\hline \multicolumn{5}{|c|}{ Block 1 rs4776338/rs7162912/rs12901071 } \\
\hline $\mathrm{T} / \mathrm{C} / \mathrm{A}$ & $321(42.6)$ & $482(44.1)$ & $1.13(0.87-1.46)$ & 0.3720 \\
\hline $\mathrm{T} / \mathrm{A} / \mathrm{A}$ & $25(3.3)$ & $9(0.8)$ & $4.69(2.13-10.37)$ & $<0.0001^{\circ}$ \\
\hline $\mathrm{C} / \mathrm{C} / \mathrm{A}$ & $97(12.9)$ & $155(14.2)$ & $1.06(0.76-1.48)$ & 0.7428 \\
\hline $\mathrm{C} / \mathrm{A} / \mathrm{A}$ & $159(21.1)$ & $225(20.6)$ & $1.19(0.89-1.61)$ & 0.2424 \\
\hline $\mathrm{C} / \mathrm{C} / \mathrm{G}$ & $22(2.9)$ & $1(0.1)$ & 37.18 (4.95-279.09) & $<0.0001^{2}$ \\
\hline $\mathrm{C} / \mathrm{A} / \mathrm{G}$ & $129(17.1)$ & $218(20.0)$ & Reference & \\
\hline \multicolumn{5}{|c|}{ Block 2 rs12910698/rs4776339 } \\
\hline $\mathrm{G} / \mathrm{A}$ & $477(62.9)$ & $674(60.8)$ & $1.62(0.85-3.06)$ & 0.1367 \\
\hline$T / G$ & $260(34.3)$ & $393(35.5)$ & $1.51(0.79-2.89)$ & 0.2078 \\
\hline $\mathrm{G} / \mathrm{G}$ & $14(1.9)$ & $32(2.9)$ & Reference & \\
\hline
\end{tabular}

asignificant $(P<0.01)$ values are in bold.

study from Kim et al. ${ }^{34}$ indicated $1 \mathrm{p} 31$ region as susceptibility loci for KD. Furthermore, PELI1 gene locus in the 2 p13.3 region was confirmed to associate with the development of CAL in the $\mathrm{KD}$ patients. Importantly, genome-wide association study results from the Taiwanese population suggest another three novel susceptibility loci for $\mathrm{KD}^{35}$ The human SMAD3 gene is located on chromosome 15, which has not been identified by genome-wide association study as a risk locus in the Asian population. These observations in combination with those of the present study support the presence of ethnic differences or environmental factors for the susceptibility or severity of KD.

Shimizu et al. ${ }^{22}$ firstly identified that 16 SNPs in six genes (TGFB2, TGFBR2, SMAD1, ENG, ACVRL1 and SMAD3) associated with the susceptibility of $\mathrm{KD}$. The significance of genetic variation in the three genes (SMAD3, TGFB2 and TGFBR2) could be replicated in the multiethnic transmission disequilibrium test (TDT) analysis from the independent United States/United Kingdom/Australia subjects. In our study, we found one of the seven polymorphisms in SMAD3 (rs1438386) associated with the susceptibility to KD in the Taiwanese population. Regarding the CAL formation and IVIG treatment response, Shimizu et al. ${ }^{22}$ reported that genetic variants in TGFB2, TGFBR2 and SMAD3 consistently influenced the coronary artery outcome in two independent, non-overlapping cohorts. However, the SNPs identified from these two cohorts were not identical. In 
this study, there were no polymorphisms in the TGF $\beta 2$, TGFBR2 or SMAD3 that were significantly associated with the CAL formation and IVIG treatment response in KD patients in the Taiwanese population. We acknowledge the limitations in our study. We only genotyped the SNPs that have been shown to be associated with the KD susceptibility in multiethnic TDT analysis from the independent United States/ United Kingdom/Australia subjects.

Therefore, the rare causal genetic polymorphisms at the TGF- $\beta$ pathway would not be detected in this study. In addition, the SNP of $S M A D 3$ identified in this study is located in intron. Future studies are needed to address the mechanism by which SMAD3 genotypes contribute to the development of KD.

In conclusion, our results indicated that a SNP (rs1438386) and haplotypes in the TGF- $\beta$ pathways associated with the susceptibility to KD in the Taiwanese population. However, we did not provide evidence to support the role of polymorphisms in the TGF- $\beta$ pathways leading to CALs in this study. We attribute this to the different genetic backgrounds in the populations, due to ethnic differences in the distribution of polymorphisms in the TGF- $\beta$ pathways. Consistent with this, KD susceptibility loci identified from the genome-wide association studies exhibited distinct distributions in different populations.

\section{CONFLICT OF INTEREST}

The authors declare no conflict of interest.

\section{ACKNOWLEDGEMENTS}

This study was partly supported by funding from Excellence for Cancer Research Center grant, Department of Health, Executive Yuan, Taiwan, ROC (NO.DOH100-TD-C-111-002). This work was supported by a grant from the National Science Council, Taiwan, ROC (NSC 100-2320-B-037-002) to WCChang. This work was supported by a grant from Chang Gung Memorial Hospital, Taiwan (CMRPG891441, CMRPG891241 and CMRP8A0121). I am grateful to Edward Hsi (Kaohsiung Medical University Hospital) for providing valuable suggestions in this study.

1 Kawasaki, T., Kosaki, F., Okawa, S., Shigematsu, I. \& Yanagawa, H. A new infantile acute febrile mucocutaneous lymph node syndrome (MLNS) prevailing in Japan. Pediatrics 54, 271-276 (1974).

2 Wang, C. L., Wu, Y. T., Liu, C. A., Kuo, H. C. \& Yang, K. D. Kawasaki disease: infection, immunity and genetics. Pediatr. Infect. Dis. J. 24, 998-1004 (2005).

3 Burns, J. C. \& Glode, M. P. Kawasaki syndrome. Lancet 364, 533-544 (2004).

4 Kuo, H. C., Liang, C. D., Wang, C. L., Yu, H. R., Hwang, K. P. \& Yang, K. D. Serum albumin level predicts initial intravenous immunoglobulin treatment failure in Kawasaki disease. Acta Paediatr. 99, 1578-1583 (2010).

5 Park, Y. W., Han, J. W., Park, I. S., Kim, C. H., Cha, S. H., Ma, J. S. et al. Kawasaki disease in Korea, 2003-2005. Pediatr. Infect. Dis. J. 26, 821-823 (2007).

6 Huang, W. C., Huang, L. M., Chang, I. S., Chang, L. Y., Chiang, B. L., Chen, P. J. et al. Epidemiologic features of Kawasaki disease in Taiwan, 2003-2006. Pediatrics 123, e401-e405 (2009).

7 Nakamura, Y., Yashiro, M., Uehara, R., Oki, I., Kayaba, K. \& Yanagawa, H. Increasing incidence of Kawasaki disease in Japan: nationwide survey. Pediatr. Int. 50, 287-290 (2008).

8 Liang, C. D., Kuo, H. C., Yang, K. D., Wang, C. L. \& Ko, S. F. Coronary artery fistula associated with Kawasaki disease. Am. Heart J. 157, 584-588 (2009).

9 Newburger, J. W., Takahashi, M., Gerber, M. A., Gewitz, M. H., Tani, L. Y., Burns, J. C. et al. Diagnosis, treatment, and long-term management of Kawasaki disease: a statement for health professionals from the Committee on Rheumatic Fever, Endocarditis and Kawasaki Disease, Council on Cardiovascular Disease in the Young, American Heart Association. Circulation 110, 2747-2771 (2004).
10 Jibiki, T., Terai, M., Shima, M., Ogawa, A., Hamada, H., Kanazawa, M. et al. Monocyte chemoattractant protein 1 gene regulatory region polymorphism and serum levels of monocyte chemoattractant protein 1 in Japanese patients with Kawasaki disease. Arthritis Rheum. 44, 2211-2212 (2001).

11 Weng, K. P., Hsieh, K. S., Hwang, Y. T., Huang, S. H., Lai, T. J., Yuh, Y. S. et al. IL-10 polymorphisms are associated with coronary artery lesions in acute stage of Kawasaki disease. Circ. J. 74, 983-989 (2010).

12 Onouchi, Y., Onoue, S., Tamari, M., Wakui, K., Fukushima, Y., Yashiro, M. et al. CD40 ligand gene and Kawasaki disease. Eur. J. Hum. Genet. 12, 1062-1068 (2004).

13 Burns, J. C., Shimizu, C., Shike, H., Newburger, J. W., Sundel, R. P., Baker, A. L. et al. Family-based association analysis implicates IL-4 in susceptibility to Kawasaki disease. Genes Immun. 6, 438-444 (2005).

14 Onouchi, Y., Ozaki, K., Buns, J. C., Shimizu, C., Hamada, H., Honda, T. et al. Common variants in CASP3 confer susceptibility to Kawasaki disease. Hum. Mol. Genet. 19, 2898-2906 (2010).

15 Kuo, H. C., Yu, H. R., Juo, S. H., Yang, K. D., Wang, Y. S., Liang, C. D. et al. CASP3 gene single-nucleotide polymorphism (rs72689236) and Kawasaki disease in Taiwanese children. J. Hum. Genet. 56, 161-165 (2011).

16 Chen, S. Y., Wan, L., Huang, Y. C., Sheu, J. J., Lan, Y. C., Lai, C. H. et al. Interleukin-18 gene $105 \mathrm{~A} / \mathrm{C}$ genetic polymorphism is associated with the susceptibility of Kawasaki disease. J. Clin. Lab. Anal. 23, 71-76 (2009).

17 Lin, Y. J., Wan, L., Wu, J. Y., Sheu, J. J., Lin, C. W., Lan, Y. C. et al. HLA-E gene polymorphism associated with susceptibility to Kawasaki disease and formation of coronary artery aneurysms. Arthritis Rheum. 60, 604-610 (2009).

18 Jhang, W. K., Kang, M. J., Jin, H. S., Yu, J., Kim, B. J., Kim, B. S. et al. The CCR5 $(-2135 \mathrm{C} / \mathrm{T})$ polymorphism may be associated with the development of Kawasaki disease in Korean children. J. Clin. Immunol. 29, 22-28 (2009).

19 Kuo, H. C., Yang, K. D., Juo, S. H., Liang, C. D., Chen, W. C., Wang, Y. S. et al. ITPKC single nucleotide polymorphism associated with the Kawasaki disease in a Taiwanese population. PloS. One 6, e17370 (2011).

20 Onouchi, Y., Gunji, T., Burns, J. C., Shimizu, C., Newburger, J. W., Yashiro, M. et al. ITPKC functional polymorphism associated with Kawasaki disease susceptibility and formation of coronary artery aneurysms. Nat. Genet. 40, 35-42 (2008).

21 Burgner, D., Davila, S., Breunis, W. B., Ng, S. B., Li, Y., Bonnard, C. et al. A genomewide association study identifies novel and functionally related susceptibility loci for Kawasaki disease. PloS. Genet. 5, e1000319 (2009).

22 Shimizu, C., Jain, S., Davila, S., Hibberd, M. L., Lin, K. O., Molkara, D. et al. Transforming growth factor-beta signaling pathway in patients with Kawasaki disease. Circ. Cardiovasc. Genet. 4, 16-25 (2011).

23 Taylor, A. W. Review of the activation of TGF-beta in immunity. J. Leukoc. Biol. 85, 29-33 (2009).

24 Christ, M., McCartney-Francis, N. L., Kulkarni, A. B., Ward, J. M., Mizel, D. E., Mackall, C. L. et al. Immune dysregulation in TGF-beta 1-deficient mice. J. Immunol. 153, 1936-1946 (1994).

25 Leask, A. \& Abraham, D. J. TGF-beta signaling and the fibrotic response. FASEB J. 18, 816-827 (2004).

26 Chen, C. L., Liu, I. H., Fliesler, S. J., Han, X., Huang, S. S. \& Huang, J. S. Cholesterol suppresses cellular TGF-beta responsiveness: implications in atherogenesis. J. Cell Sci. 120, 3509-3521 (2007)

27 Kuo, H. C., Liang, C. D., Yu, H. R., Wang, C. L., Lin, I. C., Liu, C. A. et al. CTLA-4, position $49 \mathrm{~A} / \mathrm{G}$ polymorphism associated with coronary artery lesions in Kawasaki disease. J. Clin. Immunol. 31, 240-244 (2010).

28 Kuo, H. C., Wang, C. L., Liang, C. D., Yu, H. R., Huang, C. F., Wang, L. et al. Association of lower eosinophil-related T helper 2 (Th2) cytokines with coronary artery lesions in Kawasaki disease. Pediatr. Allergy Immunol. 20, 266-272 (2009).

29 Yu, H. R., Kuo, H. C., Sheen, J. M., Wang, L., Lin, I. C., Wang, C. L. et al. A unique plasma proteomic profiling with imbalanced fibrinogen cascade in patients with Kawasaki disease. Pediatr. Allergy Immunol. 20, 699-707 (2009).

30 Shulman, S. T., De Inocencio, J. \& Hirsch, R. Kawasaki disease. Pediatr. Clin. North Am. 42, 1205-1222 (1995).

31 Kuo, H. C., Wang, C. L., Liang, C. D., Yu, H. R., Chen, H. H., Wang, L. et al. Persistent monocytosis after intravenous immunoglobulin therapy correlated with the development of coronary artery lesions in patients with Kawasaki disease. J. Microbiol. Immunol. Infect. 40, 395-400 (2007).

32 Kuo, H. C., Yang, K. D., Liang, C. D., Bong, C. N., Yu, H. R., Wang, L. et al. The relationship of eosinophilia to intravenous immunoglobulin treatment failure in Kawasaki disease. Pediatr. Allergy Immunol. 18, 354-359 (2007).

33 Das, L. \& Levine, A. D. TGF-beta inhibits IL-2 production and promotes cell cycle arrest in TCR-activated effector/memory T cells in the presence of sustained TCR signal transduction. J. Immunol. 180, 1490-1498 (2008).

$34 \mathrm{Kim}$, J. J., Hong, Y. M., Sohn, S., Jang, G. Y., Ha, K. S., Yun, S. W. et al. A genome-wide association analysis reveals $1 \mathrm{p} 31$ and 2 p13.3 as susceptibility loci for Kawasaki disease. Hum. Genet. 129, 487-495 (2011).

35 Tsai, F. J., Lee, Y. C., Chang, J. S., Huang, L. M., Huang, F. Y., Chiu, N. C. et al. Identification of novel susceptibility loci for Kawasaki disease in a Han Chinese population by a genome-wide association study. PloS. One 6, e16853 (2011). 